\title{
Editorial
}

\section{Appreciating David Barker (1938-2013)}

\author{
Matthew W. Gillman ${ }^{\text {a, b }}$ Vincent W.V. Jaddoe ${ }^{c}$ \\ ${ }^{a}$ Obesity Prevention Program, Department of Population Medicine, Harvard Medical School and Harvard \\ Pilgrim Health Care Institute and ${ }^{b}$ Department of Nutrition, Harvard School of Public Health, Boston, Mass., USA; \\ 'Departments of Epidemiology and Pediatrics, Erasmus University Medical Center, Rotterdam, The Netherlands
}

Professor David J.P. Barker passed away on August 27, 2013 at the age of 75 years. Neither of us worked in his Southampton MRC Epidemiology Unit, although we were grateful recipients of his hospitality when visiting. We were not among his closest collaborators. Each of us coauthored only one publication with him. Nevertheless, David Barker was a key figure in our professional lives and in those of many other scientists and policy makers as well as the public.

Professor Barker created and fostered a whole field as few people do. More than anyone, he was the catalyst for amassing a now large body of evidence to support the notion that events during early development have life-long, sometimes irreversible influences on health outcomes. He pursued this central idea with pluck, aided by serendipity [1]. At first, doubt was rampant. Even for those of us who believed that adult disease has its precursors in childhood, it seemed implausible that what happened during those ostensibly short months in utero could have lasting consequences. The entrée of one of us (M.W.G.) into this field was an unconvinced review for the BMJ of Professor Barker's first book [2], but this was followed just a few years later by a commentary containing the sub-

\section{KARGER}

E-Mail karger@karger.com

www.karger.com/anm title '... from sceptic to convert' [3]. By then, the epidemiological research that David Barker had initiated was maturing from ecological observations to cohorts with primary data collection, improved follow-up rates and better control for confounding, along with an expanding series of rich interdisciplinary investigations. Owing to the fertile ground laid by Professor Barker, we and numerous colleagues have spent the last decade or more examining the roles of maternal/fetal/infant nutrition, metabolism and other developmental factors in determining lifetime health. Today, many of the intervention studies that his work fostered, aimed at changing the in utero or early childhood environment, are coming to fruition.

Today, the field of developmental origins of health and disease, and its cousin the life-course approach to chronic disease, are in the mainstream. $\mathrm{DOHaD}$ has its own society and journal. In the USA, many of the National Institutes of Health issue funding announcements around this theme, and in the European Union, major international consortia are devoted to identifying adverse exposures in early life and to translating findings into intervention and policy. The principles that David Barker espoused hold major implications for low- and middle-
(C) 2013 S. Karger AG, Basel

0250-6807/13/0634-0291\$38.00/0
Dr. Matthew W. Gillman

133 Brookline Avenue, 6th floor Boston, MA 02215 (USA)

E-Mail matthew_gillman@hms.harvard.edu 
income countries in the 21st century. Obstetricians talk to pediatricians outside of the delivery room and epigeneticists, experimental physiologists, epidemiologists, evolutionary biologists and economists collaborate with one another. Newsweek and TIME have published compelling cover stories, lay books are popular and Hillary Clinton talks of the first 1,000 days.

Often it takes a single-minded individual to sail successfully against the prevailing winds. David Barker, fortunately for the rest of us, was that. He was also generous with his time and ideas. He mentored a new generation of scientists, many of whom are leaders in their own right. We all owe Professor David Barker an incalculable debt of gratitude for his creativity, ideas and dedication.

\section{References}

1 Barker D: The midwife, the coincidence, and the hypothesis. BMJ 2003; 327:1428-1430.

2 Barker DJP: Mothers, Babies and Health in Later Life, ed 1. Edinburgh, Churchill Livingstone, 1994.

3 Gillman MW, Rich-Edwards JW: The fetal origin of adult disease: from sceptic to convert. Paediatr Perinat Epidemiol 2000;14:192-193. 